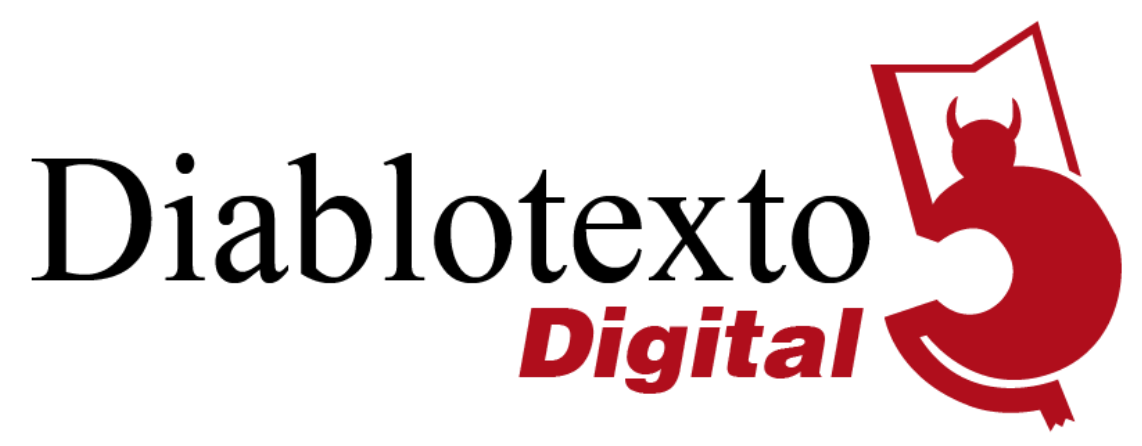

\title{
Identidad, negación y emancipación: una lectura de Reivindicación del Conde don Julián de Juan Goytisolo desde la dialéctica hegeliana
}

\author{
Identity, Negation and Emancipation: Reading Juan Goytisolo's Reivindicación \\ del Conde don Julián Through the Lens of the Hegelian Dialectic \\ CARLOS IGLESIAS-CRESPO \\ KING'S COLLEGE, UNIVERSITY OF CAMBRIDGE
}

\begin{abstract}
Resumen: Este artículo propone un análisis de la emancipación del yo narrativo de Reivindicación del Conde don Julián (1970) de Juan Goytisolo desde la dialéctica hegeliana. Para desarrollar nuestra hipótesis, ofrecemos una breve exposición de los principios de la dialéctica hegeliana como paso previo al análisis propiamente dicho, donde se propone una nueva manera de entender la novela que permite matizar las opiniones de aquellos críticos que consideran que Don Julián es un proyecto fallido. Nada más lejos de la realidad: una perspectiva hegeliana permite constatar cómo Don Julián, pese a sus tensiones estructurales, ideológicas y subjetivas, no es víctima de su aparente cierre sobre sí misma, sino que supone una pieza fundamental para comprender la evolución de la identidad del yo narrativo en la obra de Goytisolo.
\end{abstract}

Palabras clave: Juan Goytisolo, Don Julián, Identidad, Dialéctica, Hegel

Abstract: This paper brings forth an analysis of the emancipation of the narrative subject in Juan Goytisolo's Reivindicación del Conde don Julián (1970) through the lens of the Hegelian dialectic. A brief summary of the Hegelian dialectic is followed by the analysis, which proposes a new way of understanding the novel that questions the critical view of Don Julián as a failed project: a Hegelian perspective underlines how Don Julián, despite its structural, ideological and subjective tensions, is not a victim of its own closure, but a crucial work in the evolution of the narrative subject's identity in Goytisolo's oeuvre.

Key words: Juan Goytisolo, Don Julián, Identity, Dialectic, Hegel 


\title{
Introducción
}

En 1970 se publica en México la novela de Juan Goytisolo Reivindicación del Conde don Julián 1 . Su objetivo, según el autor, era realizar una "agresión alienada, esquizofrénica, onírica" contra la España del franquismo y sus mitos en un momento en el que, en la cúspide de los años del desarrollismo económico y la apertura al exterior, el aparato propagandístico de la dictadura se esforzaba por enmascarar su realidad represiva ${ }^{2}$. El deseo de agresión nace del desengaño originado por la toma de consciencia de "la imposibilidad de cambiar la realidad política española debido, en parte, al aburguesamiento y modernización de una sociedad que se europeizaba y, también, a la escasa implantación popular del Partido Comunista dentro de la Península" (Escudero, 1994: 12). A este desengaño se une una decepción con los cauces de la narrativa española de los años 50 y 60, todavía anclada en un realismo crítico y social que, pese a sus esfuerzos, no hace mella en el corazón ideológico de la dictadura (un sentimiento compartido por Luis Martín Santos y su Tiempo de silencio de 1962) ${ }^{3}$. El desengaño y la decepción, que quedarían plasmados en la primera entrega del llamado "Tríptico del mal" o "Trilogía de la traición", Señas de identidad-publicada en México en 1966-, pronto se tornan en obsesión, como confesaría el propio Goytisolo a Julio Ortega:

\begin{abstract}
La interpretación mítica, justificativa de la historia de España me obsesionaba desde hace años. Es difícil vivir en una ciudad como Tánger, enfrentado a la presencia cercana de la costa española, sin evocar la figura legendaria de don Julián y soñar en una «traición» gloriosa como la suya. Mi despego de los valores oficiales del país había llegado a tal extremo que la idea de su profanación, de su destrucción simbólica, me acompañaba día y noche (Goytisolo, 1977: 292).
\end{abstract}

Obsesión, traición, profanación, destrucción. Goytisolo construye en torno a estas coordenadas la identidad auto-ficcional de su yo narrativo en Reivindicación del Conde don Julián, ejemplo paradigmático de lo que Gonzalo Luque González ha llamado recientemente la "estética de la oposición"; a

\footnotetext{
${ }^{1}$ Este artículo es una versión revisada y ampliada de la comunicación presentada en el XVII Congreso Internacional ALEPH, celebrado en Valencia en junio de 2021. Deseo expresar mi agradecimiento a Miguel Ángel Lama, Victoria Alzina y Johanna Jeung por su apoyo, así como a los evaluadores anónimos por sus útiles sugerencias.

2 Ver la entrevista a cargo de Claude Couffon (1975: 117-118).

${ }^{3}$ Sobre este punto, ver Sanz Villanueva $(1984,158-164)$ y Black $(2001: 17-44)$.
} 
saber, la formulación de la literatura como crimen, en virtud de la cual "el artista debe renegar de la sociedad que lo ha generado; así, además de dejar atrás lo que los ha repelido, trata de examinar y destruir su propia genealogía, el pasado o el mundo del que reniega" (Luque González, 2018: 223-225)4 . Tradicionalmente, la crítica ha interpretado esta novela como un ataque tan feroz como radical en sus postulados que excluye cualquier escenario posible más allá de la negación (identitaria, estética, ideológica, normativa) de 10 español-el íncipit de la novela, en este sentido, da cuenta fehaciente de los deseos del yo julianesco: "tierra ingrata, entre todas espuria y mezquina, jamás volveré a ti" (Goytisolo, 1985: 83) ${ }^{5}$.

El objetivo de este artículo es examinar y matizar el alcance de dicha oposición en Reivindicación del Conde don Julián desde una perspectiva dialéctica en clave hegeliana ${ }^{6}$. Así pues, frente a las posturas que realzan la negación como el horizonte de la identidad del yo narrativo de Don Julián ${ }^{7}$, en las próximas páginas pondré de relieve cómo, pese a su ataque esencialista a la España franquista, la novela (especialmente su primera parte) alberga una pulsión que supera la dicotomía del mito y el contra-mito y que busca trascender la barrera identitaria de la negación. Dicha pulsión, en primer lugar, tiene su fundamento en la influencia abiertamente reconocida de las ideas de

\footnotetext{
${ }^{4}$ Apunta Luque González que la concepción que equipara al escritor con el criminal no puede entenderse sin la obra de Jean Genet, el delincuente literario por excelencia. Como es bien sabido, Genet y Goytisolo no solo mantuvieron una estrecha relación de amistad (el más fehaciente testamento de su vínculo es el hecho de que ambos están enterrados juntos en Larache [https://www.abc.es/cultura/abci-juan-goytisolo-enterrado-junto-genet-larache201706052228 noticia.html]), sino que además Goytisolo es heredero directo de la obra de aquel (Luque González, 2018: 224). El mejor punto de partida sobre la influencia que ejerce Genet sobre Goytisolo es la obra de ensayo del propio Goytisolo, especialmente su Genet en el Raval (2008).

${ }^{5}$ La oposición identitaria e ideológica que Don Julián establece contra España y Franco por medio de la deconstrucción discursiva, ejecutada en el terreno de lo surreal y lo onírico, ha sido tratada por Romero (1973), Durán (1975), Vargas Llosa (1975), González (1984), Piedrahita Rook (1985), Levine (1985), Six (1990), Black (2001), Frohlich (2003), Lemus (2007) o Luque González (2018). La oposición estético-literaria (especialmente contra el canon) ha sido objeto de estudio de Orringer (1975), Navajas (1977), Ugarte (1980/1982), Braun (1987), Prado (2000) o Davis (2012). La oposición a los discursos normativos en sentido amplio ha sido estudiada por Pérez (1979) Epps (1992), Romo (2011) o Polet (2015).

${ }^{6} \mathrm{Mi}$ análisis está en deuda con el trabajo de Cibreiro (1994) y Navajas (1998), quienes sugieren dicha posibilidad.

7 Así lo han argumentado Schwartz (1975), Epps (1992: 294-295), Escudero (1998: 89) o Ribeiro de Menezes (2005: 86-89), por mencionar tan solo algunos ejemplos representativos.
} 
Américo Castro sobre la génesis ideológica de Reivindicación del Conde don Julián; desde esta perspectiva, el objetivo ulterior de la novela sería la creación de una nueva España como fuente de una identidad emancipada, descrita por Théophile Koui (2015: 149) como "una España nueva que sea la superación de todos los valores obsoletos que contaminan el sujeto cultural" ${ }^{\text {. En segundo }}$ lugar, la pulsión superadora de la novela se articula en torno a la dialéctica hegeliana en su vertiente tanto lógica (tesis-antítesis-síntesis) como subjetiva (señor-siervo); este último aspecto será el objeto principal de estudio de mi análisis, que desarrollaré entre estos dos polos. Para llevar esta labor a buen puerto, resumiré brevemente los principios teóricos de la dialéctica hegeliana como paso previo al análisis propiamente dicho, donde destacaré cómo la lectura aquí propuesta permite profundizar sobre los objetivos ideológicos de Reivindicación del Conde don Julián y su construcción de una identidad emancipada.

\section{La dialéctica en la filosofía hegeliana}

\section{La tríada dialéctica}

Como es bien sabido, la filosofía idealista del alemán Georg Wilhelm Friedrich Hegel (1770-1831) se construye sobre la dialéctica, cuyos tres momentos son popularmente conocidos como "tesis", "antítesis" y "síntesis". El proceder dialéctico es un método expositivo de naturaleza lógica que postula cómo diversas categorías, conceptos, juicios, etc., demuestran una naturaleza inherentemente contradictoria que hace que evolucionen necesariamente hacia

\footnotetext{
${ }^{8}$ Como explica Linda Gould Levine, Goytisolo se inserta "de lleno en medio de la polémica acerba y todavía viva entre Américo Castro y Sánchez Albornoz": frente a las ideas del último sobre la continuidad milenaria de una españolidad esencialmente cristiana, Castro reivindica la importancia crucial de lo árabe y lo judío en la configuración histórica de España-una aportación que quedaría oscurecida por la agresión de la tercera cultura de la Península (1985: 23-25). Durante la redacción de Reivindicación del Conde don Julián, Goytisolo llegó a mantener una esporádica relación epistolar con Castro en los últimos años de la vida de este a propósito de las ideas de la novela. Ver al respecto la edición de su correspondencia a cargo de Escudero (1997), así como el reciente estudio de López-Ríos (2018).

9 Aunque Hegel no utilizó estos términos con los que Karl Popper (1940) describió sucintamente su filosofía, son útiles desde una perspectiva metodológica para describir el proceder dialéctico, como Michael Forster argumenta en su estudio sobre la dialéctica hegeliana (1993: 131). Por tanto, en este trabajo hemos optado por utilizar estos términos para lograr una mayor claridad expositiva, sin renunciar puntualmente al vocabulario técnico de la lógica hegeliana.
} 
sus antónimos; el resultado de la interacción entre las posiciones anteriores da pie a una nueva categoría que las unifica y las supera, lo que resulta en un encadenamiento jerárquico y cíclico—pues la tercera categoría inevitablemente adolecerá de nuevas contradicciones inherentes-que desencadena en última instancia en una categoría tanto totalizante como totalizadora, la Idea Absoluta (Forster, 1993: 130-32).

En las secciones 80 a 82 de la Enciclopedia de las ciencias filosóficas en compendio, obra de madurez del alemán donde este ofrece la visión global de su sistema (Valls Plana, 1997: 11), Hegel explica la dialéctica de la siguiente manera. En un primer momento, contamos con el momento abstracto-racional o tesis (Hegel, 1997: 183): aquí, el concepto, categoría o forma en cuestión se presenta de manera estable, determinada y aparentemente final. A este momento le sigue el llamado momento dialéctico o antítesis, definido como "el propio superar de tales determinaciones finitas y su pasar a sus opuestas" (Hegel, 1997: 183). Este pone de manifiesto las contradicciones implícitas e inherentes a la tesis por medio de su opuesto, que lo confronta de manera disruptiva; sin embargo, este opuesto hace gala de contradicciones igual de excluyentes que las anteriores. Finalmente, se abre paso un tercer momento que rompe el impasse, el denominado especulativo, racional-positivo o síntesis, que "aprehende la unidad de las determinaciones en su oposición, lo afirmativo que se contiene en la disolución de ellas y en su pasar" (Hegel, 1997: 184). Es aquí donde se produce lo que en terminología hegeliana se conoce como aufhebung, la superación de las contradicciones previas gracias a una tercera categoría que las preserva a la vez que las descarta (Forster, 1993: 132).

\section{La dialéctica del señor y el siervo}

Aunque la dialéctica lógica es aquella conformada por la tesis, la antítesis y la síntesis, al tratar la filosofía hegeliana cabría hablar de dialécticas en plural, ya que junto a la tríada anterior encontramos otro de los aspectos más influyentes del pensamiento del alemán, la famosa dialéctica del señor y el siervo de la 
Fenomenología del espíritu (secciones 187 a 194) ${ }^{10}$. Como es bien sabido, esta consiste en lo siguiente. Dos entidades entran en conflicto-una "lucha a muerte" (Hegel, 2006: 290)—como forma primera de relación. Este es un tira y afloja en el que dichas entidades compiten por reafirmarse exclusivamente por medio de la otra. Ambas buscan el reconocimiento de su libertad. El riesgo radica en que dicho reconocimiento no es mutuo, y por ello se enzarzan, dispuestas a destruirse; no obstante, dado que la destrucción supondría la eliminación de la posibilidad de reconocimiento (Stern, 2002: 81-83)-lo que daría lugar a la nada-, una de las dos cede y adopta la posición de siervo en relación dialéctica ante el señor (Houlgate, 2012: 98-99).

En esta coyuntura, el señor se muestra como sujeto libre y completo frente al siervo al ejercer su poder sobre él; no obstante, como Stern (2002: 83) apunta, esta situación esconde una paradoja. El conflicto inicial se debía a la búsqueda de reconocimiento por parte del otro; sin embargo, este solo podía darse entre iguales (Hegel, 2006: 290). Al convertir el reconocimiento en servidumbre, el señor descubre que no puede revalidarlo, ya que su posición cosifica al siervo; este, en cambio, aunque cosificado y subyugado, entra en contacto con el mundo y es capaz de mediarlo como su objeto (Hegel, 2006: 295-296). Por tanto, el siervo es capaz de realizarse y reafirmarse como individuo al reconocerse en el producto de su trabajo, cobrando conciencia de su aparente cosificación (Hegel, 2006: 300). Según Alexandre Kojève, el siervo alcanza la libertad formal y la ruptura de su cadena por medio de este proceso, y obtiene su emancipación real en la exaltación, defensa y práctica frente al amo de dicha libertad. Esto es posible debido a que, mientras que el señor es una entidad monolítica, el esclavo es un sujeto proteico; como resultado, su trabajo y su contacto con el mundo le ofrece una oportunidad para transformarlo conforme a su nueva identidad emancipada (Kojève, 1969: 49-51).

\footnotetext{
10 Esta dialéctica se conoce también bajo el nombre de la dialéctica del amo y el esclavo. En este caso, hemos escogido los términos que Jiménez Redondo emplea en su traducción de la Fenomenología del espíritu (2006), dado que capturan mejor la dinámica de carácter feudal sobre la que Hegel erige su propuesta.
} 


\section{Más allá de la oposición: identidad y emancipación en Reivindicación del Conde don Julián}

Si aplicamos las premisas de la tríada dialéctica a la lectura de la novela de Goytisolo, resulta evidente que la tesis la configuran aquellos elementos contra los que Don Julián milita; a saber, los mitos y la manipulación de la historia de la España franquista, la idea de un canon nacional que preserva las esencias de lo español, y los discursos normativos puestos al servicio de la opresión del sujeto y su identidad. Estos serán introducidos de manera progresiva a lo largo de la primera parte en un crescendo ininterrumpido; si, como sugiere Genaro Pérez (1979: 44), la novela se estructura a la manera de una sonata en cuatro movimientos, la primera parte de la novela introducirá por tanto los leitmotivs a desarrollar. Por consiguiente, prestaré a continuación especial atención a la formulación de la tesis en la primera parte de Don Julián, pues es aquí donde la novela plantea sus premisas mayores.

Como he apuntado en otra ocasión, la ya mencionada primera oración de la novela- "tierra ingrata, entre todas espuria y mezquina, jamás volveré a ti”-introduce de lleno los polos temáticos de la novela: la disidencia y el exilio del protagonista, quien se posiciona "frente a la fiera, lejos de sus colmillos y zarpazos" (Goytisolo, 1985: 86), íntimamente calificada como "Madrastra" (Goytisolo, 1985: 88) e impersonalmente como "la costa enemiga" (Goytisolo, 1985: 93) ${ }^{11}$. La densa red semántica que Goytisolo teje en torno a la animalización (la fiera), la alienación (la madrastra) y la cosificación (la costa enemiga) pone de manifiesto la ferocidad implacable del enemigo a batir, caracterizado a su vez como un "país de siervos y señores" que se identifica metonímicamente con los "tricornios de charol", símbolo de la organización jerárquica, estamental y represiva de la España franquista (Goytisolo, 1985: 88). Así pues, pese a que esta se presenta en apariencia como una "sociedad de consumo" moderna, su muy publicitado desarrollo económico no es suficiente para encubrir la realidad que subsiste en "esa España que engorda, sí, pero que sigue muda" (Goytisolo, 1985: 119).

\footnotetext{
${ }^{11}$ Lo explico en mi reciente artículo en el Anuario de Estudios Filológicos (2021: 112).
} 
La realidad de la represión cubierta bajo el velo del desarrollismo es quizás el aspecto ideológico más evidente de la tesis, pero a la vez resulta el más elusivo en el espacio tangerino en el que se desarrolla la novela. Frente a este halo indeterminado que se cierne sobre el protagonista desde la distancia - en su relato de su rutina diaria como exiliado, el yo le reconoce al lector que "Ios beneficios de la ínclita sociedad de consumo no se manifiestan aún en esas tierras y la moda no uniforma ni iguala a los miembros de las distintas capas" (Goytisolo, 1985: 94)—, el canon literario y su manifestación material en los voluminosos tomos de la biblioteca a la que acude el protagonista en la primera parte resulta un aspecto más fácilmente atacable a la par que tangible. Después de todo, el canon constituye un rasgo más del relato mítico y esencialista de la dictadura, que se apropia de toda una genealogía literaria que va "del romancero a Lope, de Lope a Federico : hasta los queridísimos poetas de hoy" en aras de una españolidad osificada en esas "obras pletóricas de sustancia inconfundiblemente vuestra : estrellas fijas del impoluto firmamento hispano : del espíritu unido por las raíces a lo eterno de la casta" (Goytisolo, 1985: 107-108), como así lo han apuntado estudiosos como Sobejano (1977), Ugarte (1980/1982) o Davis (2012).

Junto a las características de implacabilidad y osificación, la novela representa la tesis a través del personaje multiforme de don Álvaro Peranzules ${ }^{12}$. Este aparece por primera vez en la novela como "un abejorro [...] con bigotillo alfonsino, gabardina, gafas: quijada borbónica, manos regordetas [...] personaje de novela de don Torcuato Luca de Tena" que acosa al protagonista y trata de identificarlo (Goytisolo, 1985: 129-132). Este re-aparece unas páginas más tarde, identificado nuevamente por su "quijada larga, nariz borbónica, bigotito perfectamente horizontal en forma de tildes de "eñe»", transformado en don Álvaro Peranzules-Figurón, quien retiene momentáneamente al protagonista y le obliga a escuchar una retahíla de soflamas de corte falangista a propósito de la figura de Séneca: "tienes que hacerlo [leer a Séneca] : hay que desterrar las actitudes cómodas e

12 Sobre las transformaciones de este personaje, consultar el estudio de Ramos (1981). 
intrascendentes : someter la realidad a los imperativos absolutos del espíritu : a un orden jerárquico, vertical" (Goytisolo, 1985: 153) ${ }^{13}$. Sobre estas líneas maestras, Goytisolo desarrollará múltiples metamorfosis de este personaje, a quien transforma en Séneca y en el Figurón como trasunto de Franco a lo largo de la novela (Prado, 2000: 58-61).

Así pues, Don Julián identifica la tesis a combatir en torno a la ferocidad de esa madrastra siempre en una distancia ambigua y peligrosa, la pesada rigidez del canon y la implacabilidad ubicua de don Álvaro-Séneca-Figurón para conformar la idea global de una España monolítica, esencialista, conservadora y opresiva. Estas características terminan por solidificarse finalmente en la figura multiforme de don Álvaro, que deviene en la tercera parte de la novela en una "máscara no, mascarón de proa forjado por lentos siglos de rictus rictus estereotipado, inmóvil" (Goytisolo, 1985: 230), síntesis y símbolo del continuismo histórico español tan denostado por Goytisolo y su maestro Castro.

Sin embargo, como postula el pensamiento lógico de Hegel, toda tesis alberga inevitablemente una negación dialéctica; en este caso, la idea rígida y excluyente de España que construye el franquismo desde el punto de vista de Don Julián y su protagonista-narrador remite necesaria e irremediablemente a su Otro, aquello que el discurso oficial rechaza y denigra, como uno de sus elementos definitorios ${ }^{14}$. Es por ello precisamente por lo que el yo narrativo de la novela moldea su identidad siguiendo el ejemplo del traidor por antonomasia de la historiografía oficial española desde tiempos inmemoriales ${ }^{15}$, convertido en ese "nuevo conde don Julián, fraguando sombrías traiciones" (Goytisolo, 1985: 89) que Goytisolo evoca al comienzo de la primera parte y que desarrollará su actividad, tanto en compañía de un nuevo Tariq como en solitario, hasta el clímax final de la cuarta y última parte de la novela. Por tanto,

\footnotetext{
${ }^{13}$ La parodia de la retórica senequista-falangista de este episodio ha sido apuntada por Linda Gould Levine en su edición (1985: 152-154), a la que me remito en este punto.

${ }^{14}$ Ver Frohlich (2003: 62) y Viestenz (2014: 70-71) al respecto.

${ }^{15}$ La figura del conde don Julián aparece por primera vez en la historiografía medieval en la llamada Crónica mozárabe del 754. Segura González (2010) ofrece un panorama bastante completo de las fuentes medievales, tanto musulmanas como cristianas, que tratan el tema de la pérdida de España, entre las que destaca la Estoria de Espanna alfonsí por ser uno de los textos con los que Goytisolo dialoga intertextualmente.
} 
la identificación del protagonista con la figura mítica del conde de Ceuta permite a la novela poner de relieve por medio de un relato histórico alternativo la contradicción interna ya no solo del discurso ideológico de la dictadura, sino también de las ideas espurias de continuismo histórico y pureza nacional que surgen a partir de la narrativa de la Reconquista ${ }^{16}$.

Para Javier Escudero, dicha alternativa supone un problema, ya que, frente al nacionalcatolicismo y sus mitos, "Goytisolo propone un discurso igual de extremado en el cual se exaltan el componente musulmán y el hebreo, aunque este en menor medida, y se denigra el cristiano" (Escudero, 1998: 89). Este choque de extremos, no obstante, posibilita una síntesis capaz de superar la dicotomía excluyente entre la tesis y la antítesis que surge precisamente de su yuxtaposición. A nuestro parecer, Goytisolo explora y explota la fragilidad de la identidad nacional en Don Julián, sacudida por la confrontación con el Otro en los términos descritos por Paul Ricoeur (2004: 81). ${ }^{17}$ Al atacar esta línea de flotación de manera radical, la novela sortea un riesgo identificado por el propio autor- "los escritores que se enfrentan al mito [desde la razón] carecen de la fuerza de atracción del mito que combaten", como le confesara el barcelonés en 1971 a Claude Couffon (Couffon, 1975: 117). Por esta razón, el ataque frontal al mito debe ser ejecutado por medio de la creación de un nuevo mito capaz de establecer una verdadera antítesis. Esta queda plasmada con claridad durante el medine $o^{18}$ del protagonista en la primera parte cuando, mientras este contempla un gallo moribundo, encontramos la siguiente declaración:

\footnotetext{
${ }^{16}$ El término "Reconquista" en sí mismo es anacrónico y sintomático de una visión que busca legitimar la idea de una España de esencias puras, fundamentada exclusivamente en la herencia visigoda y cristiana. Esta visión fue uno de los pilares del ideario mítico, histórico y político del franquismo-ver al respecto los estudios de García-Sanjuán $(2018,2020)$.

17 Sobre la fragilidad de la identidad tanto individual como colectiva, Ricoeur sentencia que "[i]t is a fact that the other, because other, comes to be perceived as a danger for one's own identity, our identity as well as my identity" (Ricoeur 2004: 81).

${ }_{18}$ Como es bien sabido, el verbo medinear es invención del propio Goytisolo. El sentido del verbo, como apunta Hisham Aidi, es el acto de deambular sin rumbo por los espacios marginales (2017: 25). Aunque Goytisolo aplica este verbo sobre todo para describir su modus operandi en la vida real, reconoce que algunas de sus novelas se construyen formalmente sobre esta idea, como es el caso de Don Julián-ver al respecto la entrevista al autor firmada por Santiago de Lucca para el periódico El Litoral (26 de marzo de 2016) [https://www.ellitoral.com/index.php/diarios/2016/03/26/nosotros/NOS-05.html].
} 
la violencia, la violencia siempre : jalonando discretamente tu camino : convincente y súbita : anulando de golpe el orden fingido, revelando la verdad bajo la máscara, catalizando tus fuerzas dispersas y los donjulianescos proyectos de invasión : traición grandiosa, ruina de siglos : ejército cruel de Tariq, destrucción de la España sagrada (Goytisolo, 1985: 126). ${ }^{19}$

A mi parecer, dicha antítesis no supone la destrucción por la destrucción. Al contrario, la referencia estratégica a la traición julianesca y su invasión sugiere que estamos ante un caso de lo que Paul Ricoeur denomina una "violencia fundadora" (Ricoeur, 2004: 82) ${ }^{20}$. Es decir, de la misma manera que la traición legendaria del conde Julián fue un evento fundacional para la tradición épica e historiográfica alfonsí, que la conceptualizó como el hecho que posibilitó el renacer de una nueva España a partir de las ruinas del reino visigodo, consideramos que en Don Julián se da el primer paso (violento) para sentar las bases de una nueva identidad tanto individual como nacional que se nutre de las tesis de Américo Castro y que surge de las ruinas del pasado mítico ${ }^{21}$. El resultado, por tanto, pasa necesariamente por invadir una vez más la península para ser alcanzado, como así se desarrollará posteriormente en la parte III:

\author{
ocuparás iglesias, bibliotecas, cuarteles, el monasterio de Yuste, San Lorenzo del \\ Escorial, el Cerro de los Ángeles \\ liberarás la mezquita de Córdoba, la Giralda, la Alhambra \\ arrasarás el granadino palacio de Carlos Quinto \\ sentarás tu harén en el jardín del Retiro \\ fomentarás la apostasía muladí y la propaganda alcoránica (Goytisolo, 1985: 208).
}

\footnotetext{
${ }^{19}$ La expresión "destrucción de la España sagrada" sintetiza una de las vigas maestras de la novela. Esta aparece por primera vez como el título del diálogo que Emir Rodríguez Monegal mantiene con Goytisolo en 1967, donde el autor declara que su objetivo es llevar a cabo «una traición personal, una violación propia» (1967: 48). Como apunta Viestenz (2014: 70), "the title of the article is indeed a citation from Conde Julián". Romero (1973) ofrece un valioso análisis de cómo Goytisolo trata de articular esta destrucción en Don Julián.

${ }^{20}$ La tesis de Ricoeur sobre la violencia fundadora es la siguiente: "It is a fact that there is no historical community that has not arisen out of what can be termed an original relation to war. What we celebrate under the heading of founding events are, essentially, violent acts legitimated at first by a precarious state of right, acts legitimated, at the limit, by their very antiquity, by their age" (Ricoeur, 2004: 82).

${ }^{21}$ Sobre la conceptualización de la traición como hecho fundacional en la época alfonsí, es indispensable el estudio de Geraldine Coates (2009). También es de utilidad el monográfico de Elizabeth Drayson (2007), centrado en la evolución y recepción de la figuras del rey don Rodrigo, la Cava y el conde don Julián.
} 
Por tanto, Goytisolo emplea el anverso del mito para construir su proyecto antitético, en virtud del cual, según Cibreiro, "puede infiltrarse en el proceso histórico y elevar su venganza a una magnitud tan legendaria como la historia de España misma" (1994: 13). Se ha de notar, sin embargo, que esta estrategia alberga una serie de contradicciones de naturaleza dialéctica; es decir, el anti-mito se articula precisamente desde el mito. Por ello, Vargas Llosa está especialmente en lo cierto al afirmar que Don Julián es un "crimen pasional", pues "se alimenta en buena parte de lo que denuncia, está construido con materiales que aborrece" (Vargas Llosa, 1975: 171-173). La agresión a los tomos de la biblioteca es un claro ejemplo: el protagonista inserta insectos entre las páginas de las obras "de Calderón, Tirso o del con razón Vega por lo siempre llano" o "entre los lentos paisajes del Noventa y Ocho" (Goytisolo, 1985: 111-113) para profanar el canon materialmente; sin embargo, el autor recurre intertextualmente a las palabras de los autores que ataca para construir la novela-como es el caso de Unamuno, que tiene un peso especial en este sentido ${ }^{22}$. La contradicción también afecta a aquellos autores heterodoxos que Goytisolo emplea contra el canon, pues la nómina que va desde La Celestina hasta Cernuda, pasando por Góngora, Cervantes o Larra, no deja de ser una parte integral de ese mismo canon nacional. En última instancia, esta serie de contradicciones se remontan a la relación que tanto el protagonista como el autor mantienen con la lengua española: por una parte, el español es el "último lazo que, a tu pesar, te une irreductiblemente a la tribu"; sin embargo, este es el "vehículo necesario de la traición, hermosa lengua tuya: instrumento indispensable del renegado y del apóstata, esplendoroso y devastador a la vez" (Goytisolo, 1985: 143)23.

Esto supone precisamente la contradicción interna de la identidad que Goytisolo construye en Don Julián como antítesis dialéctica, exacerbada por la visión alternativa de la historia en la que el autor inserta su proyecto. Pese a

${ }^{22}$ Braun señala que "[a]pproximately 40 items, ranging from long sentences to snippets, can be attributed to Unamuno, who surpasses all the others in the number of separate citations" (1987: 40).

${ }^{23}$ El uso y estatus del lenguaje en Don Julián ha sido estudiado, por mencionar tan solo algunos ejemplos, por Durán (1975), Orringer (1975), Black (2000), McClennen (2004) y Polet (2015). 
ello, la novela negocia estas contradicciones por medio de un ejercicio estratégico de la violencia, que, como he apuntado más arriba, permite abrir una tercera vía. Así pues, bajo la violencia destructora-fundadora que se postula en la parte I y que se desarrollará a lo largo de la novela encontramos un proceso dialéctico de naturaleza hegeliana que, pese a todo, afirma la posibilidad de una síntesis positiva y del movimiento de superación del aufhebung en Don Julián. Esta visión permite matizar las conclusiones de aquel sector de la crítica que sostiene que la novela es un proyecto fallido-es el caso, por ejemplo, de Michael Ugarte (1982: 78), que comenta que en Don Julián "the old myth remains intact as the new one emerges. The outcome of this never-ending battle is ambiguous. Reality becomes lost in the linguistic recreation and interplay between an old mythology and a new one"; de Alison Ribeiro de Menezes (2005: 90), quien afirma que Don Julián es "a novel of unfulfilled possibilities"; o Stanley Black (2001: 114), que considera que nada cambia realmente ni en la intradiégesis ni en la extradiégesis de la novela, lo que genera una estasis, un punto muerto. A nuestro parecer, nada más lejos de la realidad: Goytisolo sienta unas bases sólidas para la creación de una nueva identidad emancipada en el resto de la obra de su periodo medio (Juan sin tierra, Makbara y Paisajes después de la batalla), lograda precisamente por la emancipación formal del sujeto al final de Don Julián. Para ello, es necesario reflejar cómo la dialéctica del señor y el siervo hace posible esta operación.

En primer lugar, la búsqueda de destrucción en Don Julián genera una situación de excepción, la lucha a muerte que precede a la configuración de la dialéctica, en la que el exiliado adopta la posición del siervo frente al aparato de la dictadura, que se postula como señor. La situación es la siguiente: si el proyecto de Goytisolo destruye efectivamente a su oponente, este se vería efectivamente anulado a su vez. Esta es una paradoja que el barcelonés comparte en cierta medida con su amigo Jean Genet y que es una de las características definitorias de la poética del complot propia de las vanguardias literario-políticas de las que participa Goytisolo, como así lo han señalado Ricardo Piglia (2002) y Gonzalo Luque (2018): "La vanguardia rechaza el sistema pero lo necesita para su definición” (Luque González, 2018: 226). De 
igual manera, si la España franquista destruye a Goytisolo, esta pierde su Otro simbólico contra el que afirmar su autoridad; como ya viera Gonzalo Navajas, "Cuanto mayor es el rechazo de esa tradición, tanto mayor es la vinculación con ella. El Esclavo (el texto) necesita del Señor (la España tradicional) para ser, al mismo tiempo que el Señor requiere de la oposición a ella para justificar la persecución de sus oponentes" (Navajas, 1998: 187).

Las aportaciones tanto de Luque González como de Navajas, pese a que reconocen el impulso dialéctico de la novela, realzan la indefensión del protagonista de Don Julián frente a un enemigo—la dictadura franquista—que goza, como apuntarían las tesis de Max Weber (2013: 54-56), del monopolio del uso de la violencia; una violencia ejercida tanto sobre su persona-lo que lo lleva al exilio en Tánger-como sobre su obra—como "el abejorro" le recuerda en la primera parte al protagonista, este fue autor de un documental que nunca vio la luz: "buceando en la memoria, cerca, muy cerca de la diana : con sonrisa de galán de cine español de los años cuarenta : estólido y tenaz / preparaba usted un documental" (Goytisolo, 1985: 131). ${ }^{24}$ Podría parecer, por tanto, que la dialéctica no es una posibilidad real y que todo el proceso se ve abocado irremediablemente a un estancamiento en el que el siervo tan solo puede ser siervo o, como máximo, convertirse en nuevo señor sin otra opción para poder romper el impasse. En definitiva, esta es la esencia del "Sartrean reading of the Hegelian master-slave dialectic" que Ribeiro de Menezes (2005: 63) le achaca a la novela y que en cierto modo comparten aquellos críticos que, como he apuntado más arriba, consideran que Don Julián no está a la altura de sus

\footnotetext{
${ }^{24}$ Como señala Linda Gould Levine, es bastante probable que Goytisolo esté refiriéndose a "varias partes de Señas de identidad y la profesión de Álvaro Mendiola como autor de un documental sobre la emigración española. Aunque Pere Gimferrer ha afirmado que el narrador de Don Julián es «inidentificable», es obvio que su voz condenatoria es una proyección y continuación de la de Mendiola" (Levine, 1985: 132, nota al pie n. 96). Dicho documental es el tema principal de los capítulos tercero y séptimo de Señas de identidad. Cabe apuntar que, como indica Ribeiro de Menezes, "another of Goytisolo's works from this period, La resaca (1958), coincided with the release of a documentary on the poverty of southern Spain, Notes sur l'émigration, which was shown at the Teatro del Corso in Milan"; dicho documental sería saboteado y atribuido a Goytisolo, episodio que el autor novelizará a su vez en el primer capítulo de Señas (Ribeiro de Menezes 2005: 63; Persino 1999: 151-152).
} 
propias expectativas ${ }^{25}$. A mi parecer, esta visión crítica niega la oportunidad que la posición del siervo le brinda al protagonista, pues es precisamente desde dicha posición que la novela articula su propuesta de emancipación.

Así como Hegel explica en la sección 193 de la Fenomenología del espíritu que el siervo ha de replegarse en sí mismo para poder alcanzar su verdadera independencia a través de su mediación-aprehensión de la realidad (Hegel, 2006: 297), el exilio tangerino de Goytisolo/Álvaro Mendiola puede entenderse como ese estado de retiro en el que el sujeto es capaz de construir su identidad emancipada por medio del discurso. Desde esta perspectiva, la Reivindicación del Conde don Julián media la realidad de la España franquista de los años del desarrollismo sin caer en las trampas del realismo social de los años 50 y 60 , pues su objetivo es atacar el punto ciego del mito en la búsqueda de su superación más allá de la crítica y la denuncia.

Esta última consideración es fundamental, ya que articula un punto de encuentro clave entre el concepto de libertad hegeliano y el proyecto de emancipación de Don Julián. Como ha explicado recientemente Todd McGowan, la libertad para Hegel tiene su origen en la negación de la autoridad externa del señor por parte del siervo, pero esta libertad tan solo se alcanza cuando el siervo es capaz de postularse a sí mismo más allá de su oposición. Este ir más allá de la negación es lo que permite al sujeto fundamentar y sustanciar su libertad en sí mismo. Dicho proceso se lleva a cabo de manera dialéctica: es necesario forzar la negación hasta sus últimos límites, de tal manera que sea posible dejarla atrás. De esta manera, el sujeto es capaz de convertir aquello que niega en una herramienta para su libertad (McGowan, 2019: 155-172).

Don Julián desarrolla de este proceso hasta sus últimas consecuencias. Así pues, la antítesis mítica de la traición permite dejar en evidencia la nula validez de los mitos que combate, a la vez que marca todo mito-incluido el

25 Como explica James Ogilvy en su estudio sobre la modificación de la dialéctica hegeliana en la obra de Sartre y en el psicoanálisis francés post-freudiano, frente al proceso dialéctico emancipador entre amo y esclavo en Hegel, Sartre niega la posibilidad de resolución de la dialéctica, siendo esta un callejón sin salida y condenada a la osificación, cuya única modificación posible sería un cambio de papeles (1980: 211). 
propio-como un constructo contradictorio, ficticio y superable ${ }^{26}$. Goytisolo materializa su negación extrema de diversas formas a lo largo de la narración. Aunque ya he analizado algunas de sus manifestaciones, cabe recapitular los cuatro puntos de ataque desarrollados en la novela a lo largo de sus cuatro partes; a saber, la profanación física del canon en su visita a la biblioteca en la parte I (Goytisolo, 1985: 104-144); la ridiculización de naturaleza "castrista" de las pesquisas sobre las esencias españolas a propósito de la figura de Séneca, realizada por medio de la parodia de las obras de Menéndez Pidal, Ángel Gavinet, Pérez de Ayala, Sánchez Albornoz u Ortega y Gasset en la parte II (1985: 181-195); la nueva invasión musulmana que el protagonista, llevando a cabo su papel de conde don Julián redivivo, lidera en la parte III (1985: 201 288); y, finalmente, mediante la violación homicida de su ego infantil, identificado con lo traicionado, en la parte IV (1985: 271-300).

Como ya he mencionado, parte de la crítica cree que el horizonte de esta negación, materializado en el cierre de la novela, implica que Goytisolo en última instancia no logra llevar a cabo su aparente objetivo-la ya mencionada "destrucción de la España sagrada" (Goytisolo, 1985: 126). Sin embargo, la hipótesis que venimos defendiendo permite llegar a una conclusión distinta: precisamente porque Don Julián puede ser entendida como un ejercicio dialéctico, la España sagrada debe ser preservada en cierto modo-por ejemplo, por medio de la apropiación intertextual o a través la modificación deliberada de los códigos compartidos de la lengua-para poder ser superada. Es más, gracias a esa preservación y superación de naturaleza hegeliana podría afirmarse que el yo narrativo logra articular su proyecto y alcanzar, aunque con ciertas limitaciones, el ideal de una identidad emancipada como un sujeto proteico que se postula más allá de la mera negación, materializando por tanto el proceso de liberación del siervo; así lo anticipa Goytisolo en la primera parte de Don Julián:

dueño proteico de tu destino, sí, y lo que es mejor, fuera del devenir histórico [...] sin reclamar tu puesto en el nada eucarístico banquete: sin aspirar a las disputadas

${ }^{26}$ Me remito al análisis de Cibreiro (1994) sobre este punto, cuyas conclusiones comparto. 
migajas : en los limbos de un tiempo sin fronteras : en el piadoso olvido : libre de seguir tus pasos donde tus pasos te llevan (Goytisolo, 1985: 100).

Esta caracterización que hace el protagonista de sí mismo contiene por tanto los mimbres de su liberación final. Así pues, el cierre circular de la novela no solo da cuenta precisamente de la emancipación formal del sujeto, sino que, siguiendo una vez más la propuesta musicológica que mencionaba al comienzo del análisis, si Don Julián tiene una forma estructural que imita la de una sonata, la cita anterior es un claro leitmotiv que es desarrollado y modificado a lo largo de la novela y que concluye catárticamente en la declaración final. Revirtiendo el exilio negativo del comienzo, Goytisolo/Mendiola se apropia de sus limitaciones impuestas y las convierte en el instrumento de su emancipación, casi con una actitud nietzscheana que abraza el eterno retorno: "mañana será otro día, la invasión recomenzará" (Goytisolo, 1985: 304). Es decir, en la repetición del ejercicio de invasión y el abanico de posibilidades que esta ofrece se encuentra, paradójicamente, su libertad.

\section{Conclusiones: la evolución de una identidad emancipada}

Llegados a este punto, podemos concluir que la Reivindicación del Conde don Julián ejecuta un paso crucial para entender la evolución de la identidad del yo narrativo en la obra de Goytisolo hasta su paréntesis autobiográfico (Coto vedado y En los reinos de taifa, de 1985 y 1986 respectivamente) a mediados de la década de los años 80 . El proyecto del barcelonés en estos años consiste, entre otros aspectos, en convertir al sujeto narrativo en la fuente de su libertad, lo que configura en última instancia su identidad. En Don Julián, Goytisolo ejecuta esta operación mediante la internalización dialéctica de aquello a lo que se opone: al calor de la fricción del mito y el contra-mito, se fragua la posibilidad de emancipación a través de su superación. En Juan sin tierra, dicha dialéctica queda cerrada, como el final de la obra pone de manifiesto:

Los que no me entendéis, dejad de seguirme.

Nuestra comunicación ha terminado.

Estoy definitivamente al otro lado, 
con los parias de siempre, afilando el cuchillo (Goytisolo, 2005: 29). ${ }^{27}$

En Paisajes después de la batalla no quedará sino un sujeto autosuficiente que se realiza en sí mismo y en cuanto le rodea:

yo: el escritor

yo: lo escrito (Goytisolo, 2005: 1046).

\section{Bibliografía}

AIDI, Hisham (2017). "Juan Goytisolo: Tangier, Havana and the Treasonous Intellectual", Middle East Reports, vol. 282, pp. 19-31.

BLACK, Stanley (2001). Juan Goytisolo and the Poetics of Contagion: The Evolution of a Radical Aesthetic in the Later Novels. Liverpool: Liverpool University Press.

BRAUN, Lucille (1987). "The «intertextualization» of Unamuno and Juan Goytisolo's Reivindicación del conde don Julián", Hispanófila, vol. 89, pp. 39-56.

CiBREIRO, Estrella (1994). "Reivindicación del conde don Julián y la trilogía de Juan Goytisolo: la dialéctica entre el individuo, la historia y el discurso literario", Hispanic Journal, vol. 15, n. ${ }^{\circ}$ 1, pp. 7-19.

COATES, Geraldine (2009). Treacherous Foundations: Betrayal and Collective Identity in Early Spanish Epic, Chronicle, and Drama. Woodbridge, Tamesis, Serie A: Monografías, 281.

CoufFon, Claude (1975). “Una reivindicación”. En Gonzalo Sobejano (ed.), Juan Goytisolo. Madrid: Fundamentos, pp. 117-120.

DAvIS, Stuart (2012). Writing and Heritage in Contemporary Spain. The Imaginary Museum of Literature. Woodbridge: Tamesis, Serie A: Monografías, 309.

De LuCCA, Santiago (2016). “Conversaciones con el Conde Don Julián”. El Litoral [versión online], 26-03-2016, https://www.ellitoral.com/index.php/diarios/2016/03/26/nosotros/NOS05.html [Fecha de consulta: 18-11-2021].

Drayson, Elizabeth (2007). The King and the Whore. King Roderick and La Cava. New York: Palgrave Macmillan.

DurÁN, Manuel (1975). “El lenguaje de Juan Goytisolo”. En Gonzalo Sobejano (ed.), Juan Goytisolo. Madrid: Fundamentos, pp. 53-69.

EFE (2017). "Juan Goytisolo, enterrado junto a Genet en Larache". $A B C$ [versión online], 05-06-2017, https://www.abc.es/cultura/abci-juangoytisolo-enterrado-junto-genet-larache-

201706052228 noticia.html?ref=https\%3A\%2F\%2Fwww.google.com\%2 F [Fecha de consulta: 17-11-2021].

EPPS, Brad (1992). "The Politics of Ventriloquism: Cava, Revolution and Sexual Discourse in Conde Julian”, MLN (1992), vol. 107, n.ำ 2, pp. 274-297.

${ }^{27}$ Esta es la traducción que ofrece el propio Goytisolo en la introducción al volumen 3 de sus Obras completas de las líneas finales de Juan sin tierra, famosamente escritas en caracteres árabes. 
ESCUDERO, Javier (1994). Eros, mística y muerte en Juan Goytisolo (1982 1992). Granada: Instituto de Estudios Almerienses.

Escudero, Javier (ed.) (1997). El epistolario. Cartas de Américo Castro a Juan Goytisolo, 1968-1972. Valencia: Pre-Textos.

EscuDERO, Javier (1998). "Juan Goytisolo: De apóstata a iluminado", Revista Hispánica Moderna (1998), vol. 51, n.ำ 1, pp. 87-101.

FoRSTER, Michael (1993). "Hegel's Dialectical Method". En Frederick Beiser (ed.), The Cambridge Companion to Hegel. Cambridge: Cambridge University Press, pp. 130-170.

GaRcíA-SANJUÁN, Alejandro (2018). "Rejecting al-Andalus, exalting the Reconquista: historical memory in contemporary Spain", Journal of Medieval Iberian Studies (2018), vol. 10, pp. 127-145.

GaRcíA-SANJUÁN, Alejandro (2020). "Weaponizing Historical Knowledge: The Notion of Reconquista in Spanish Nationalism", Imago Temporis. Medium Aevum (2020), vol. XIV, pp. 133-162.

GonZÁleZ, Bernardo Antonio (1984). "The Character and his Time: From Juegos de manos to Reivindicación del Conde don Julián", Revista Canadiense de Estudios Hispánicos, vol. 9, n.1, pp. 31-44.

GoYtisolo, Juan (1967). "Destrucción de la España sagrada", Mundo Nuevo, vol. 12, pp. 44-60.

GoYtisolo, Juan [1970] (1985). Reivindicación del Conde don Julián. Edición de Linda Gould Levine. Madrid: Cátedra, Letras Hispánicas 220.

GOYTISOLO, Juan (1977). Disidencias. Barcelona: Seix Barral.

Goytisolo, Juan (2005). Obras completas, vol. 3. Barcelona: Círculo de Lectores / Galaxia Gutenberg.

HEGEL, Georg Wilhelm Friedrich [1817] (1997). Enciclopedia de las ciencias filosóficas en compendio. Traducción de Ramón Valls Plana. Madrid: Alianza.

HEGEL, Georg Wilhelm Friedrich [1807] (2006). Fenomenología del espíritu. Traducción de Manuel Jiménez Redondo. Valencia: Pre-Textos.

Houlgate, Stephen (2012). Hegel's "Phenomenology of Spirit": A Reader's Guide. London: Bloomsbury Academic.

IGLESIAS-CRESPO, Carlos (2021). "El pacto onírico en Don Julián y Paisajes después de la batalla de Juan Goytisolo", Anuario de Estudios Filológicos, vol. 44, pp. 103-122.

KOJÈVE, Alexandre (1969). Introduction to the Reading of Hegel. Lectures on the Phenomenology of Spirit. Ithaca, NY: Cornell University Press.

Koul, Théophile (2015). "El sujeto cultural y la otredad: las dos Españas en Reivindicación del conde don Julián, de Juan Goytisolo", Sociocriticism,

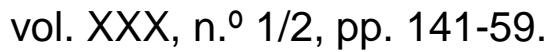

LEMUS, Víctor (2007). "«Tradición» y alteridad en Reivindicación del conde don Julián, de Juan Goytisolo", Recorte. Revista de linguagem, cultura e discurso, vol. $6, \mathrm{~s} / \mathrm{n}$.

LEVINE, Linda Gould (1985). "Introducción”, En Goytisolo, pp. 9-70.

LÓPEZ-Ríos, Santiago (2018). "La génesis de Reivindicación del conde don Julián a la luz de la correspondencia Américo Castro-Juan Goytisolo". En José Teruel (ed.), Historia e intimidad. Epistolarios y autobiografía en la 
cultura española del medio siglo. Madrid / Frankfurt: Iberoamericana / Vervuert, pp. 183-197.

LUQUE GonZÁLEZ, Gonzalo (2018). "La literatura como crimen en Juan Goytisolo", Actio Nova: Revista de Teoría de la Literatura y Literatura Comparada, vol. 2, pp. 220-242.

McClennen, Sophia (2004). Dialectics of Exile. Nation, Time, Language, and Space in Hispanic Literatures. West Lafayette, IN: Purdue University Press.

McGowaN, Todd (2019). Emancipation After Hegel: Achieving a Contradictory Revolution. New York: Columbia University Press.

NAVAJAS, Gonzalo (1998). "El subparadigma español de la modernidad: Unamuno, Cernuda y Juan Goytisolo". En Derek W. Flitter (ed.), Actas del XII Congreso de la Asociación Internacional de Hispanistas, Tomo V. Birmingham: Department of Hispanic Studies, pp. 184-190.

OGILVY, James (1980). "Mastery and Sexuality: Hegel's Dialectic in Sartre and Post-Freudian Psychology", Human Studies (1980), vol. 3, n. 3, pp. 201219.

ORRINGER, Nelson (1975). "El Góngora rebelde del Don Julián de Goytisolo a Luis Eyzaguirre", INTI, Revista de literatura hispánica (1975), vol. 2, pp. 18-30.

PÉREZ, Genaro (1979). "Some leitmotifs and bridges in the sonata form structure of Juan Goytisolo's Reivindicación del conde don Julián", Hispanófila, vol. 66, pp. 41-52.

Persino, María Silvina (1999). Hacia una poética de la mirada: Mario Vargas Llosa, Juan Marsé, Elena Garro, Juan Goytisolo. Buenos Aires: Corregidor.

PIEDRAHITA ROOK, Carmen (1985). "La «toma» de la palabra por Juan Goytisolo en Reivindicación del conde don Julián", Hispanófila, vol. 84, pp. 43-50.

PIGliA, Ricardo (2002). "Teoría del Complot", Ramona. Revista de artes visuales, vol. 23, pp. 4-15.

POLET, Grégoire (2015). "Reminiscencias de Góngora y Goytisolo: la metáfora de segundo grado en Reivindicación del conde don Julián", Analecta Malacitana (AnMal electrónica), vol. 38, pp. 189-203.

POPPER, Karl (1940). "What is Dialectics", Mind (1940), vol. 49, n.o 196, pp. 403-426.

Ramos, Alicia (1981). "Las transformaciones de Don Álvaro, Figurón y Séneca en Reivindicación del Conde Don Julián", Cuadernos de investigación filológica, vol. 7, pp. 3-14.

Ribeiro de Menezes, Alison (2005). Juan Goytisolo: The Author as Dissident. Woodbridge: Tamesis, Serie A: Monografías, 211.

Ricoeur, Paul (2004). Memory, History, Forgetting. Traducción de Kathleen Blamey y David Pellauer. Chicago: The University of Chicago Press.

ROMERO, Héctor R. (1973). "Los mitos de la España sagrada en Reivindicación del Conde don Julián", Journal of Spanish Studies: Twentieth Century, vol. 1, n.ํ 3, pp. 169-85.

Romo, Leticia (2011), "Sexualizing dictatorships in La reivindicación del conde don Julian and Cola de lagartija", Chasqui, vol. 40, n.ำ 2, pp- 146-59. 
Sanz VILlanueVA, Santos (1984). Historia de la literatura española. El siglo XX: literatura actual. Barcelona: Ariel.

SchWARTZ, Kessel (1975). "Juan Goytisolo: Ambivalent Artist in Search of His Soul”, Journal of Spanish Studies: Twentieth Century, vol. 25, n.ํㅜ 3, pp. 1095-1103.

Segura GonZÁLEZ, Wenceslao (2010). "Inicio de la invasión árabe en España: fuentes documentales", Al Qantir. Monografías y Documentos sobre la Historia de Tarifa, vol. 10, pp. 1-135.

Sıx, Abigail (1990). Juan Goytisolo: The Case for Chaos. New Haven, Yale University Press.

SOBEJANO, Gonzalo (1977). "Don Julián, iconoclasta de la literatura patria", Camp de l'Arpa, vol. 43-44, pp. 7-14.

SteRN, Robert (2002). Routledge Philosophy GuideBook to Hegel and the Phenomenology of the Spirit. London / New York: Routledge.

UGARTE, Michael (1980). “Juan Goytisolo's Mirrors: Intertextuality and SelfReflection in Reivindicación del conde don Julián and Juan sin Tierra", Modern Fiction Studies, vol. 26, n. 4, pp. 613-623.

UGARTE, Michael (1982). Trilogy of Treason: An Intertextual Study of Juan Goytisolo. Columbia y Londres: University of Missouri Press.

ValLS PlanA, Ramón (1997). "Presentación del traductor". En Hegel, pp. 9-46.

VARGAS LlOSA, Mario (1975). "Reivindicación del conde D. Julián o el crimen pasional". En Gonzalo Sobejano (ed.), Juan Goytisolo. Madrid: Fundamentos, pp. 169-173.

VIESTENZ, William R. (2014). By the Grace of God: Francoist Spain and the Sacred Roots of Political Imagination. Toronto: University of Toronto Press.

Weber, Max (2013). Economy and Society, vol. 1, Editado por Guenther Roth y Claus Wittich. Berkeley: University of California Press.

Fecha de recepción: 9 de junio de 2021

Fecha de aceptación: 25 de noviembre de 2021 